\title{
COMPUTATIONAL MOLECULAR MODELLING OF 2-AMINOBENZIMIDAZOLE DERIVATIVES: STRONG SUCCESSOR OF HYPOGLYCAEMIC AGENT
}

\author{
SREEJA S. ${ }^{*}{ }^{*}$, ANTON SMITH A. ${ }^{2}$, MADAN S. ${ }^{3}$, SUNILKUMAR D. ${ }^{4}$, VANI V. ${ }^{5}$
}

1,5 Mar Dioscorus College of Pharmacy, Thiruvananthapuram, Kerala, ${ }^{2}$ Department of Pharmacy, Annamalai University, Chidambaram, Tamilnadu, ${ }^{3}$ Ezhuthachan College of Pharmacy, Thiruvananthapuram, Kerala, ${ }^{4} \mathrm{~A} J$ College of Pharmacy, Thiruvananthapuram Kerala

Email:sreejakurup08@gmail.com

Received: 23 Apr 2021, Revised and Accepted: 07 Jul 2021

\section{ABSTRACT}

Objective: The present study was aimed to design different analogues of 2-aminobenzimidazole and find the binding ability by Insilico method.

Methods: Various soft wares like Chemsketch, Molinspiration, PASS, and Discovery studio were used to design the proposed derivatives. Evaluation of binding activity against different receptors was detected and checked their physicochemical properties for binding.

Results: In this study, we designed different analogs of 2-aminobenzimidazole into a ligand having a binding affinity with alpha-glucosidase, Dipeptidyl-peptidase 4(DPP4), Peroximase proliferator-activated receptor gamma (PPAR $\gamma$ ), and Insulin-like growth factor 1(IGF-1) receptor. The designed ten derivatives showed a significant binding capacity to the concerned receptors.

Conclusion: These results pointed that the designed proposed derivatives promising hypoglycaemic activity.

Keywords: 2-aminobenzimidazole, Alpha-glucosidase, DPP4, PPAR Gamma, IGF-1, PASS, Molecular docking

(C) 2021 The Authors. Published by Innovare Academic Sciences Pvt Ltd. This is an open access article under the CC BY license (https://creativecommons.org/licenses/by/4.0/) DOI: https://dx.doi.org/10.22159/ijpps.2021v13i9.41877. Journal homepage: https://innovareacademics.in/journals/index.php/ijpps.

\section{INTRODUCTION}

Diabetes is a metabolic disorder leads to the elevated glucose level in the blood due to the insufficient secretion of insulin by pancreas [1]. Diabetic patients were shown obesity, high concentration of triglycerides or low concentration of High-Density Lipid (HDL) cholesterol and, increased maturation rate. Diabetes is characterised by hyperglycemia, polyurea weight loss and blurred vision. Prolonged diabetes led to retinopathy, nephropathy and autonomic neuropathy [2]. The $\alpha$-glucosidase receptor inhibitors [3], Dipeptidyl-peptidase 4(DPP4) inhibitors [4], Peroximase proliferator-activated receptor gamma (PPAR $\gamma$ ) agonists, and Insulin-like growth factor-1 inhibitors (IGF-1) [5] played a major role in the antidiabetic activity. Drug design is the process for the development of biophore as a lead moiety which can be modified as a drug through various processes and produced the desired action in biological system [6]. Computer-aided drug design (CADD) is a modern technique in medicinal chemistry used to predict how to convert a lead moiety into a drug, how its combine with the receptor of known 3D structures [7-11]. Computer-aided drug design (CADD) disclosed the various methods to generate a drug moiety with less time-consuming processes. Application of Computer aided drug design (CADD) in medicinal chemistry led to predict how to convert a lead moiety into a drug, how its combine with the receptor of known 3D structures. Docking is a computational method to find out the binding affinity of a lead with the receptor and to form a stable complex. In silico method succor to modify the binding mode to attain a better fit between the ligand and receptor by changing their steric and electrostatic hindrances. The top pose of the molecule having optimized energy is selected for docking into the binding sites.

The intention of ligand-protein docking is to anticipate the predominant binding mode(s) of a ligand with a protein of known three-dimensional structures.

The Structurae Activity Study (SAR) study reveals that the amino group present at $\mathrm{C} 2$ position of Benzimidazole changes the biological activity of the parent nucleus. In this research, we have developed some new derivatives of 2 -aminobenzimidazole and evaluate their hypoglycaemic activity by finding their binding capacity on different diabetic receptors like $\alpha$-glucosidase, Peroximase proliferator- activated receptor gamma (PPAR $\gamma$ ), Dipeptidyl-peptidase 4(DPP4), and Insulin like growth factor-1 (IGF-1) by means of Discovery Studio [12]. $\alpha$-glucosidase breakdown carbohydrates into glucose and other simple sugars that can be absorbed. Activation of Peroximase proliferator-activated receptor gamma (PPAR $\gamma$ ) regulates the transcription of several insulin-responsive genes, resulting in increased insulin sensitivity in adipose tissue, liver and skeletal muscle. Dipeptidyl-peptidase 4(DPP4) inhibitors inhibit the enzyme Dipeptidyl-peptidase 4(DPP4), which is responsible for the inactivation of incretin hormone such as GLP-1which interfere glucagon release. The binding energy of the proposed ligands compared with that of markedly available standard drugs.

\section{MATERIALS AND METHODS}

In this research work, we have used different software for evaluating the proposed derivatives of 2-aminobenzimidazole. ACD Lab Chemsketch was used to draw the 3D structure of ligands. This software reveals the Lipinski rule of five [13]. Molinspiration software was used for drug-likeness properties like G proteincoupled receptors ligand score, ion channel modulator, kinase inhibitor, nuclear receptor ligand, protease inhibitor and enzyme inhibitor. The prediction of biological activity of the proposed ligand was done by means of PASS (Prediction of Activity Spectra for Substances). The 2D structure of the proposed ligands was converted into Protein Data Bank (PDB) format using the OPENBABEL programme [14-16].

For Molecular Docking the 3D structures were taken from PDB (Protein Data Bank). The docking of proposed ligands and targets was carried out by Discovery Studio. The binding energy of ligands was evaluated in terms of negative CDocker energy [17].

\section{Insilico molecular modeling}

The 3D structure of the proposed ligands was drawn by ACD Lab Chemsketch. Lipinski rule of five reveals the physicochemical properties and the drug-likeness properties of the ligands which were determined using Mol inspiration software. Lipinski rule discusses the molecular weight, number of hydrogen bond donors, number of hydrogen bond acceptors, log p-value and number of 
violations. Molinsipration software exposed the G-Protein Coupled Receptors (GPCR) ligand, Ion channel modulator, a kinase inhibitor, nuclear receptor ligand, protease inhibitor, and enzyme inhibitor property of ligands. PASS software discloses the probability of the compound to be active $(\mathrm{Pa})$ or the probability of the compound to be inactive $(\mathrm{Pi})$.

\section{Molecular docking}

Docking and its visualization and analysis of affinity between the targets and ligands were analyzed by using the software BIOVIA-Discovery Studio and Discovery Studio Visualizer. Initially, the 3D structure of targets of interest was selected from the Protein Data Bank (PDB). The Protein Data Bank (PDB) ID of $\alpha$-glucosidase is 3L4T [18], Peroximase proliferator-activated receptor gamma (PPAR $\gamma)[19]$ is $4 \mathrm{HEE}$, Dipeptidyl-peptidase 4(DPP4) is 4CDC and Insulin like growth factor-1 (IGF-1) is 3NW5 Structure of targets and ligands were converted from MOL format to PDB format by using Open Babel program. The selected targets were prepared for docking by adding hydrogen atoms and water molecules and minimizing their energy. The ligands were also prepared by the removal of unwanted molecules and generating low energy ring confirmations. Several poses were generated for targets and ligands. The first pose provides the least energy and more stabilized. So the first pose was considered as top pose and the top poses of ligand and protein were docked. In docking, the active site of native ligand was selected and a minimized target was docked against minimized ligand and the 3D images of docked structures were visualized [20]. The affinity of the ligands with targets of interest was analyzed in terms of energy through docking using negative CDocker energy using Discovery Studio.

The selected hit molecules were further evaluated for favorable ADMET (Absorption, Distribution, Metabolism, Excretion, and Toxicity) characteristics by Discovery Studio software. In this, various parameters such as aqueous solubility, blood-brain barrier penetration, absorption level, and ALogP scores were analyzed [21].

\section{RESULTS}

\section{Pharmacophore modeling}

The structure of proposed derivatives drawn by ACD Chemsketch was shown in table 1.

Table 1: Structure of proposed derivatives

\begin{tabular}{|c|c|c|c|}
\hline S. No. & Compound code & Structure of compound & Name of the compound \\
\hline 1 & B1 & & $\begin{array}{l}\{[2-(1 H \text {-benzimidazol-2-ylamino })-2- \\
\text { oxoethyl }] \text { amino }\} \text { acetic acid }\end{array}$ \\
\hline 2 & B2 & & $\begin{array}{l}N \text {-(1H-benzimidazol-2-yl)-2- } \\
\text { [(benzylcarbamoyl)amino]acetamide }\end{array}$ \\
\hline 3 & B3 & & $\begin{array}{l}4-\{[2-(1 H \text {-benzimidazol-2-ylamino })-2- \\
\text { oxoethyl }] \text { amino }\} \text { benzoic acid }\end{array}$ \\
\hline 4 & B4 & & $\begin{array}{l}4-\{[2-(1 H \text {-benzimidazol-2-ylamino })-2 \text {-oxoethyl }] \text { amino }\}-2- \\
\text { hydroxybenzoic acid }\end{array}$ \\
\hline 5 & B5 & & $\begin{array}{l}N \text {-(1H-benzimidazol-2-yl })-2-(2- \\
\text { phenylhydrazinyl }) \text { acetamide }\end{array}$ \\
\hline 6 & B6 & & $\begin{array}{l}\mathrm{N} \text {-(1H-benzimidazol-2-yl)-2-(pyridin-2- } \\
\text { ylamino)acetamide }\end{array}$ \\
\hline 7 & B7 & & $\begin{array}{l}\mathrm{N} \text {-[2-(1H-benzimidazol-2-ylamino })-2 \text {-oxoethyl }] \text { pyridine- } \\
\text { 3-carboxamide }\end{array}$ \\
\hline 8 & B8 & & $\begin{array}{l}N \text {-(1H-benzimidazol-2-yl)-2-[2-(pyridin-4- } \\
\text { ylcarbonyl)hydrazinyl]acetamide }\end{array}$ \\
\hline 9 & B9 & & $\begin{array}{l}N \text {-(1H-benzimidazol-2-yl)-2-(piperidin-4- } \\
\text { ylamino)acetamide }\end{array}$ \\
\hline 10 & B10 & & $\begin{array}{l}N \text {-(1H-benzimidazol-2-yl)-2-[(pyrimidin-4- } \\
\text { ylmethyl)amino]acetamide }\end{array}$ \\
\hline
\end{tabular}

The Lipinski rule analysis and drug-likeness properties such as G-protein Coupled Receptors Ligand score, Ion channel modulator, Kinase inhibitor, nuclear receptor-ligand protease inhibitor, and Enzyme inhibitor scores were analyzed by Molinspiration ChemInformatic software is shown in (table 2 and 3). 
Table 2: Lipinski's rule analysis of selected proposed 2-aminobenzimidazole derivatives and standard drugs

\begin{tabular}{|c|c|c|c|c|c|}
\hline Compounds & M. W. & n. HDO & n. HDA & $\log P$ & n. violation \\
\hline B1 & 248.24 & 4 & 7 & -0.94 & 0 \\
\hline B2 & 323.36 & 4 & 7 & 2.13 & 0 \\
\hline B3 & 310.31 & 4 & 7 & 2.69 & 0 \\
\hline B4 & 326.31 & 5 & 8 & 2.69 & 0 \\
\hline B5 & 281.32 & 4 & 6 & 2.54 & 0 \\
\hline B6 & 267.29 & 3 & 6 & 1.88 & 0 \\
\hline B7 & 295.30 & 3 & 7 & 0.88 & 0 \\
\hline B8 & 310.32 & 4 & 8 & 0.58 & 0 \\
\hline B9 & 273.34 & 4 & 6 & 0.91 & 0 \\
\hline $\mathrm{B} 10$ & 268.8 & 3 & 7 & 0.98 & 0 \\
\hline Octreotide & 10194 & 13 & 14 & 1.67 & 3 \\
\hline Acarbose & 645.61 & 19 & 14 & -5.51 & 3 \\
\hline Sitagliptin & 407.32 & 2 & 6 & 2.06 & 0 \\
\hline Pioglitazone & 356.45 & 1 & 5 & 3.07 & 0 \\
\hline
\end{tabular}

M. W. Molecular weight; n. HDO: number of hydrogen bond donor; n. HAD: Number of hydrogen acceptor

Table 3: Drug likeness properties of proposed ligands

\begin{tabular}{|c|c|c|c|c|c|c|}
\hline Compound & $\begin{array}{l}\text { GPCR } \\
\text { ligand }\end{array}$ & $\begin{array}{l}\text { Ion channel } \\
\text { modulator }\end{array}$ & $\begin{array}{l}\text { Kinase } \\
\text { inhibitor }\end{array}$ & $\begin{array}{l}\text { Nuclear receptor } \\
\text { ligand }\end{array}$ & $\begin{array}{l}\text { Protease } \\
\text { inhibitor }\end{array}$ & Enzyme inhibitor \\
\hline $\mathrm{B} 1$ & 0.12 & 0.06 & -0.20 & -0.66 & 0.01 & 0.09 \\
\hline B2 & 0.19 & 0.01 & 0.18 & -0.55 & 0.10 & -0.03 \\
\hline B3 & 0.07 & -0.05 & 0.14 & -0.44 & -0.06 & 0.02 \\
\hline B4 & 0.09 & -0.04 & 0.19 & -0.40 & -0.05 & 0.05 \\
\hline B5 & -0.08 & -0.13 & 0.13 & -1.04 & -0.24 & -0.10 \\
\hline B6 & 0.14 & 0.03 & 0.36 & -0.83 & -0.10 & 0.08 \\
\hline B7 & 0.18 & 0.05 & 0.28 & -0.71 & -0.01 & 0.02 \\
\hline B8 & 0.03 & -0.26 & 0.23 & -0.84 & -0.16 & -0.09 \\
\hline B9 & 0.36 & 0.18 & 0.25 & -0.77 & 0.18 & 0.05 \\
\hline B10 & 0.32 & 0.11 & 0.62 & -0.87 & -0.09 & 0.25 \\
\hline Octreotide & 0.26 & 0.18 & 0.25 & -0.77 & 0.18 & 0.05 \\
\hline Acarbose & -0.02 & -0.49 & -0.33 & -0.29 & 0.21 & 0.21 \\
\hline Sitaglyptin & 0.25 & -0.27 & 0.01 & -0.60 & 0.56 & -0.06 \\
\hline Pioglitazone & 0.25 & -0.51 & -0.71 & 0.64 & -0.09 & 0.05 \\
\hline
\end{tabular}

GPCR: G protein-coupled receptor

The PASS software was utilized for the prediction of biological activities of proposed compounds. The prediction results is presented as the list of activities with suitable 'Pa' (Probability to be active) and 'Pi' (Probability to be inactive) listed in the descending order of difference $(\mathrm{Pa}-\mathrm{Pi})>0$. The PASS value of proposed ligands was shown in table 4.

Table 4: PASS scores of selected proposed 2-aminobenzimidazole derivatives

\begin{tabular}{llll}
\hline Compound & Pa & Pi & Pa-Pi \\
\hline B1 & 0.257 & 0.009 & 0.248 \\
B2 & 0.756 & 0.101 & 0.655 \\
B3 & 0.382 & 0.024 & 0.358 \\
B4 & 0.725 & 0.046 & 0.679 \\
B5 & 0.711 & 0.085 & 0.626 \\
B6 & 0.282 & 0.014 & 0.268 \\
B7 & 0.759 & 0.054 & 0.705 \\
B8 & 0.537 & 0.011 & 0.526 \\
B9 & 0.737 & 0.061 & 0.676 \\
B10 & 0.728 & 0.07 & 0.658 \\
\hline
\end{tabular}

Table 5: Docking scores of selected derivatives and standard drugs on different targets

\begin{tabular}{|c|c|c|c|c|}
\hline \multirow[t]{2}{*}{ Standard drugs and proposed derivatives } & \multicolumn{4}{|c|}{-CDocker energy } \\
\hline & 3L4T & 4CDC & 4HEE & 3NW5 \\
\hline Acarbose & 15.2445 & --- & --- & \\
\hline Sitaglyptin & --- & -25.1509 & ---- & \\
\hline Pioglitazone & ---- & --- & -23.7593 & \\
\hline Octreotide & --- & $--\cdot-$ & ---- & -103.883 \\
\hline B1 & -27.2196 & -25.7454 & -31.7266 & -35.9925 \\
\hline B2 & -12.1995 & -24.0557 & -24.0677 & -24.5701 \\
\hline B3 & -29.7231 & -28.0454 & -43.0464 & -25.4024 \\
\hline B4 & -10.0413 & -22.1519 & -25.1519 & -25.5226 \\
\hline B5 & -13.992 & -25.4054 & -29.4054 & -18.3941 \\
\hline B6 & -28.5652 & -27.7986 & -42.4344 & -20.4805 \\
\hline B7 & -12.0385 & -17.4860 & -27.6506 & -20.4699 \\
\hline B8 & -10.2408 & -24.6506 & -30.1043 & -18.2205 \\
\hline B9 & -9.93638 & -19.0578 & -20.4891 & -15.9841 \\
\hline B10 & -18.087 & -23.7826 & -13.1826 & -21.1303 \\
\hline
\end{tabular}

-CDocker energy: Protein-Ligand interaction energy; 3L4T: $\alpha$-glucosidase; 4CDC: DPP4 (Dipeptidyl peptidase4); 4HEE: PPAR $\gamma$ (Peroxisome proliferator activated gamma receptor); 3NW5: Insulin like growth factor-1. 


\section{Molecular docking by discovery studio}

Docking evaluation of proposed 2-aminobenzimidazole derivatives against the targets of $\alpha$-glucosidase, Dipeptidyl peptidase 4 and Peroxisome proliferator activated receptor and Insulin like growth factor-1 inhibitor was done. Acarbose-a well-known $\alpha$-glucosidase inhibitor, sitaglyptin-an established Dipeptidyl peptidase4 inhibitor

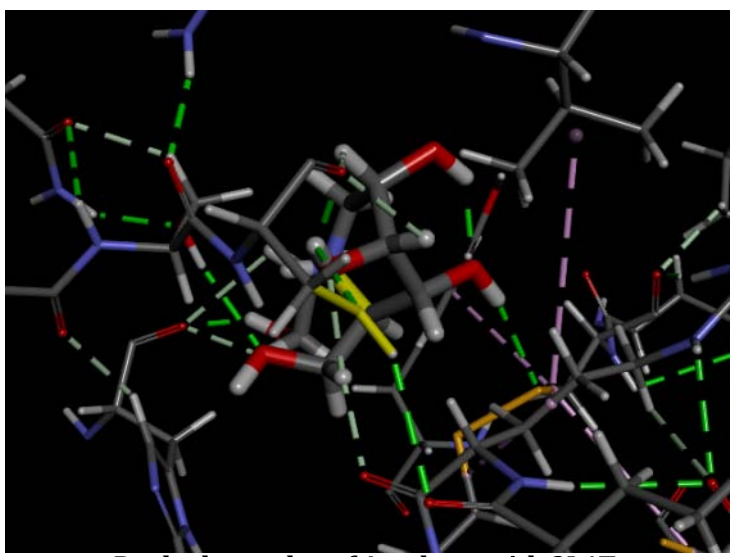

Docked complex of Acarbose with 3L4T

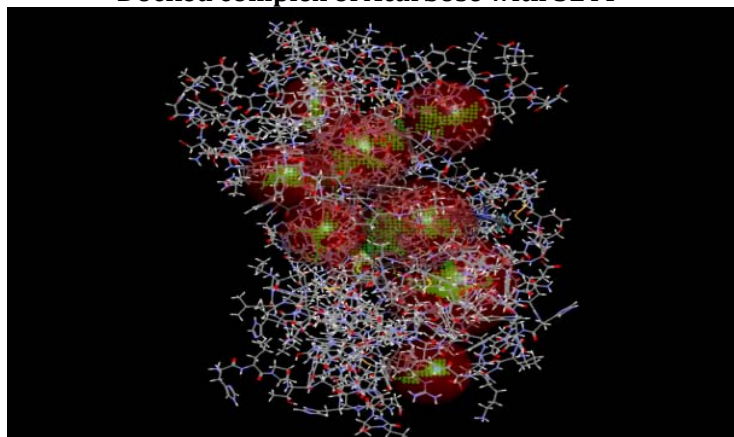

Docked complex of Sitaglyptin with 4CDC

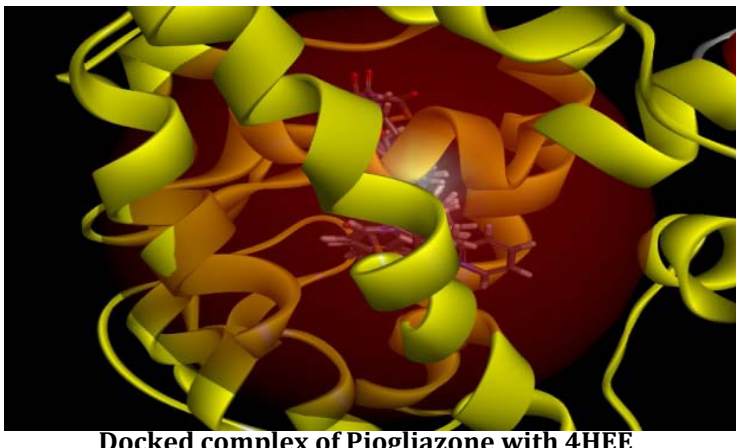

Docked complex of Piogliazone with 4HEE

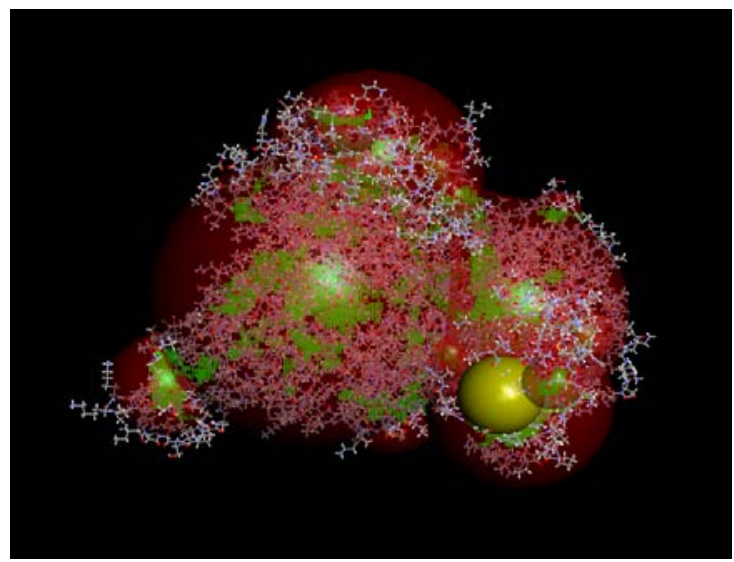

Docked complex of Octreotide with 3NW5 and the pioglitazone-a selective agonist of Peroxisome proliferator activated receptor and Octreotide-an insulin like growth factor-1 inhibitor were used as the standard drugs for comparative evaluation. The activities such as binding energy, hydrogen bonding interactions of proposed derivatives against all these three receptors were analyzed. Docking scores and images of selected standard compounds and proposed compounds were presented in table 5 and fig. 1 .
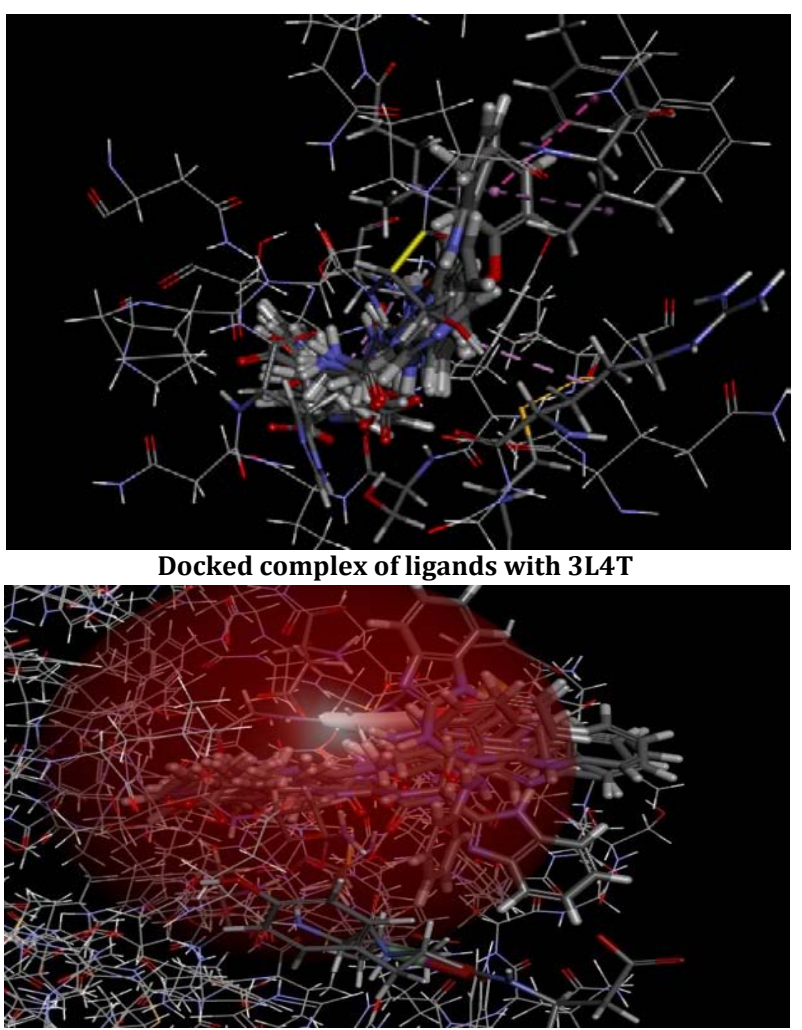

Docked complex of ligands with 4CDC
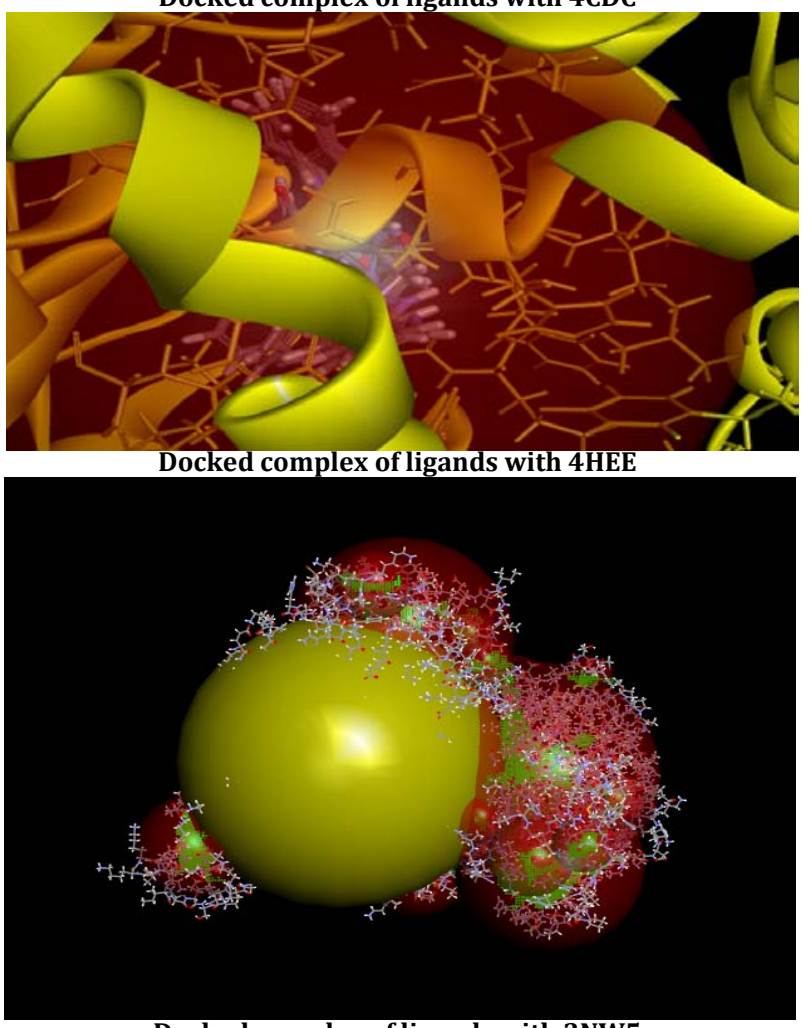

Docked complex of ligands with 3NW5

Fig. 1: Docking of standard drugs and derivatives with targets 
The active binding site of proposed derivatives and standard drugs on different receptors were presented in table 6.

Table 6: Active binding sites of active of proposed derivatives

\begin{tabular}{llll}
\hline $\begin{array}{l}\text { Standard drugs and } \\
\text { proposed derivatives }\end{array}$ & -CDocker energy & 4CDC & 4HEE \\
\cline { 2 - 4 } $\begin{array}{l}\text { Acarbose } \\
\text { Sitaglyptin }\end{array}$ & Ser74,Arg29,Cys15 & Asp1,Glu275,Cys234 & Leu330,Cys285,Arg288 \\
Pioglitazone & & & Leu330,Cys285,Ala292 \\
B1 & Pro158,Ser74,Arg29 & Asp1,Gly275,Cys234 & Met364,Leu330,Cys285, \\
B2 & Pro137,Ser74,Arg29 & Pro274,Asp1,Cys234 & Leu330,Cys285,Met329 \\
B3 & Ser74,Arg29 Pro158 & Asp1,Cys234,Phe278 & Lys367,Leu330,Cys285, \\
B4 & Ser74,Arg29,Leu160 & Asp1,Glu275,Cys234 & Ala292,Cys285,Arg288 \\
B5 & Pro137,Ser74,Arg29 & Pro279,Asp1Cys234 & Lys367,Cys285,Arg288 \\
B6 & Ser47,Arg29,Pro158 & Asp1,Glu273,Cys234 & Val333,Cys285,Arg288 \\
B7 & Val177,Ser74,Arg29 & Asp1,Glu275,Gly232 & Arg288,Met348,Cys285, \\
B8 & Leu160,Ser74,Arg29 & Ala349,Asp1,Cys234 & Leu330,Cys285,Ala292 \\
B9 & Pro158,Ser74,Arg29 & Pheu330,Cys285, Met329 \\
B10 & Lys48,Ser74,Arg29 & \\
\hline
\end{tabular}

The results of analysis of ADMET properties of the proposed derivatives with the help of Discovery studio software is presented in table 7.

Table 7: ADMET analysis of proposed 2-aminobenzimidazole derivatives

\begin{tabular}{lllll}
\hline Reference scores & & & & \\
\hline Parameters & $\mathbf{0}$ & $\mathbf{1}$ & $\mathbf{2}$ & $\mathbf{3}$ \\
\hline Aqueous solubility & Nil & Very Low & Low & Good \\
B. B. B penetration & Very high & High & Medium & Low \\
Absorption level & Optimal & Good & Medium & Low \\
A log P & $\leq 4$ & & & Very low \\
Scores obtained & & & AL & Alog P \\
Compounds & AS & BBB P & 0 & -0.041 \\
B1 & 4 & 3 & 0 & 1.646 \\
B2 & 3 & 3 & 0 & 1.962 \\
B3 & 4 & 3 & 1 & 1.72 \\
B4 & 3 & 4 & 0 & 2.393 \\
B5 & 3 & 3 & 0 & 1.62 \\
B6 & 4 & 3 & 0 & 0.581 \\
B7 & 3 & 3 & 0 & 1.81 \\
B8 & 3 & 3 & 0 & 2.75 \\
B9 & 2 & 3 & 0 & 1.092 \\
B10 & 3 & 3 & \\
\hline
\end{tabular}

AS: Aqueous solubility; BBBP: Blood brain barrier penetration; AL: Absorption level

\section{DISCUSSION}

The analysis of Lipinskirule of five pointed that all the proposed derivatives obeyed the Lipinski rule which states that the molecular weight of the compound shoulde below 500, the number of Hydrogen bond donor should be below 5,the number of Hydrogen bond acceptor should below 10 and the log P value should below 5 . It was found that all the proposed derivatives obey Lipinski rule of five or showed no number of violations and therefore they were considered as a drug and selected for further analysis [22].

Molinspiration Cheminformatics data exposed the drug-likeness properties of derivatives. It was observed that all the proposed derivatives showed significant bioactive scores on different receptors and they were act as a drug [23].

The prediction results of PASS are presented as the list of activities with suitable 'Pa' (Probability to be active) and 'Pi' (Probability to be inactive). If $\mathrm{Pa}>0.7$, the compound studied is very likely to produce this activity in experiments and the chance of being the derivative of the known therapeutic agents for this compound is also high. If $0.5<\mathrm{Pa}<0.7$, the compound studied is likely to exhibit its activity in experiments, but the probability is less and the compound is not so similar to the known therapeutic agents. If $\mathrm{Pa}<0.5$, the compound studied is unlikely to show its activity in experiments, but if the activity is confirmed in the studied compound, it might be a new chemical substance. Among 10 proposed derivatives four showed the PASS value below 0.7 and the PASS result pointed all the 10 proposed derivatives showed the value within the range and which is expected to be active [24].

The binding activity of derivatives on the receptor was determined by docking with the help of the software, Discovery studio and the affinity of the ligands with the targets were analysed in terms of energy through docking using-CDocker energy. On the basis of docking among the ten derivatives of 2-aminobenzimidazole derivatives B3, B6, B1, B8, and B5 showed less energy as compared to their standard drugs on 3L4T, 4CDC and 4HEE in the ascending order. The-CDocker energy of proposed derivatives B3, B6, B1, B8, and B5 produced less energy than that of standard drug Acarbose on 3L4T ( $\alpha$-glucosidase). The proposed derivatives B3, B6, B1, B8, and, B5 exhibit low binding energy than the standard Dipeptidyl-peptidase 4(DDP4) inhibitor drug Sitagliptin on 4CDC(DPP4 enzyme) [25]. The proposed derivatives B3, B6, B1, B8, and B5 exhibit low binding energy than the standard Dipeptidyl-peptidase 4 (PPAR $\gamma$ ) agonists drug Pioglitazone on 4 HEE(PPAR $\gamma$ receptor) [26]. It discloses that these derivatives are more stable in docked receptors. Hence can bind their concerned receptors and thereby increasing their activity to decrease the blood glucose level. In the case of the 3NW5 receptor, all the derivatives were docked to the receptors but they showed less CDocker energy than that of the standard drug Octreotide and this led to the point that the proposed derivatives are less stable in 3NW5 and they are failed to do their work.

The derivatives commonly bind with Arg29 and Ser 75 considered as active binding sites on $3 \mathrm{~L} 4 \mathrm{~T}$ which are similar to the standard one 
Acarbose. Acarbose also shows the same binding siteon 3L4T. It pointed that the derivatives having an ability to bind with $\alpha$ glucosidase receptor. The derivatives commonly bind with Asp1 and Glu 275 considered as active binding sites on 4CDC which are similar to the standard one Sitagliptin also having the same binding site to 4CDC and it pointed that the derivatives also can bind with DPP4 receptor. The derivatives commonly bind with Cys285 and Arg288 considered as active binding sites on 4HEE which are similar to the standard one Pioglitazone which also bind with the same binding site on 4HEE and showed their binding affinity towards PPAR $\gamma$ receptor.

The selected hit molecules were further evaluated for favorable ADMET (Absorption, Distribution, Metabolism, Excretion, and Toxicity) studies. The analysis of ADMET properties of proposed derivatives disclosed that the proposed derivatives B1, B3, B5, B6, and B8 showed significant aqueous solubility, BBB penetration, absorption level, and Alog $\mathrm{P}$ value which pointed that they may be considered as a good drug [27]. On the basis of Insilico design among the ten proposed derivatives four derivatives showed good binding ability towards the receptors which were concerned for antidiabetic activity.

\section{CONCLUSION}

Based on molecular modelling among the ten Benzimidazole derivatives, five showed good binding scores with $\alpha$-glucosidase, Dipeptidyl-peptidase 4(DPP 4), PPAR $\gamma$ receptors and did not give a good score on IGF-I factor. Among the ten derivatives the most five acidic compounds binds the $\alpha$-glucosidase receptor. The more aromatic derivatives showed more Dipeptidyl-peptidase 4(DPP4) inhibitor activity. The derivatives can change the conformation into horseshoe shape and it is a good for binding with Peroximase proliferator-activated receptor gamma (PPAR $\gamma$ ) receptor. All the proposed 2-aminobenzimidazole derivatives are not suitable for binding with Insulin like growth factor- 1 . All the results pointed that among the ten 2-aminobenzimidazole derivatives B1, B3, B5, B6, and B8 showed better binding affinity towards the $\alpha$-glucosidase, DPP4 and PPAR $\gamma$ receptors and hence they may nominate as a good lead in antidiabetic category.

\section{ACKNOWLEDGMENT}

We would like to thank Dr. AchuthSankar, HOD, Department of Bioinformation Technology, Kariyavattom campus, Keala Univesity, Thiruvananthapuram,and Mrs. Saraswathi, Research Scholar, Kerala University for their valuable support in the Docking procedure.

\section{FUNDING}

Nil

\section{AUTHORS CONTRIBUTIONS}

S. Sreeja carried out the whole experiment, Dr, A. Anton Smith designed the whole work, Dr, S, Mathan superwise the work, Mr. Sunil Kumar D and Mrs. Vani frame out the plan of work.

\section{CONFLICT OF INTERESTS}

\section{Declared none}

\section{REFERENCES}

1. Sodik N, Salamet E, Khayrulla B, Muhammed N. Evaluation of the antidiabetic activity and chemical composition of geranium collinum root extracts-computational and experimental investigations. Molecules 2017;22:983-2.

2. Fabiyi Edebor TD, Fasanmade AA. Evaluation of the characteristics of diabetes induced by the administration of alloxan to fructose fed wistar rat. Int J Pharm Sci Res 2019;10:881-9.

3. Kumar JA, Tiwari AK, Ali AZ, Madhusudhana K, Reddy BS, Ramakrishna $\mathrm{S}$, et al. New antihyperglycemic, alphaglucosidase inhibitory, and cytotoxic derivatives of benzimidazole. J Enzyme Inhib Med Chem 2010;25:80-6.
4. Rolee P, Mary B. Dipeptidyl peptidase (DPP-4) inhibitors in the management of diabetes. PT 2010;35:509-13.

5. Tandrasasmita OM, Wulan DD, Nailufar F, Sinambela J, Tjandrawinata RR. Glucose-lowering effect of DLBS3233 is mediated through phosphorylation of tyrosine and upregulation of PPAR $\gamma$ and GLUT4 expression. Int J Gen Med 2014;14:345-7.

6. Diogo A, Fonseca IA, Ana C, Maria D. Orphan drugs: major development challenges at the clinical stage. Drug Discovery Today 2019;10:15-7.

7. Amy C, Anderson. The process of structure based drug design. Chem Bio 2003;10:787-97.

8. Andrei T, Christopher A, Iiya WA. Docking of protein models. Protein Sci 2002;11:1888-96.

9. Antonio PP, Philip R. Idiopathic type1diabetes. J Diabetes Its Complicat 2001;15:328-5.

10. Ashutosh P, Selvam G, Jeyakandan, Ashok M. Lead discovery and lead optimazation: a useful strategy in molecular modification of lead compound in analogue design. Int J Drug Design Discovery 2011;2:458-63.

11. Athar M, Das AJ. Current trends in drug discovery: target identification to clinical development of the drug. Int Res J Pharm 2012;3:23-7.

12. Brain K, Irwin D, Dale L. Molecular docking using shape descriptors. J Com Chem 1992;13:380-97.

13. Christopher A, Lipinski. Lead-and drug-like compounds: the rule-of-five revolution. Drug Discovery Today: Technol 2004;1:337-41.

14. Christopher W, Murray, David E, Timothy R. Pro-select: combining structure based drug design and combinatorial chemistry for rapid lead discovery. J Comput Aided Mol Des 1997;11:193-207.

15. Chun MS, Shen JL, Joo CT. Recent advances in computer-aided drug design. Brief Bioinformatics 2009;10:579-91.

16. Dar A, Mir S. Molecular docking: appraches, types, applications and basic challenges. J Anal Bioanal Tech 2017;8:356-61.

17. Hughes JP, Rees S, Kalindjan SB, Philpott KL. Principles of drug discovery. Br J Pharmacol 2011;162:1239-49.

18. Ahamed Z, Prashanta CN, Perumal V, Mafibaniasadi Z. Insilico analysis of active constituents of silymarin as alphaglucosidase enzyme inhibitors in type 2 diabetes mellitus. AJPCR 2019;12:225-9.

19. Gurula H, Loganathan T, Vashum Y, Paneetselvam S, Vetrivel U, Samuel S. Insilico screening of potent PPAR gamma agonists among natural anticancer comounds of Indian orgin. AJPCR 2016;9:320-4.

20. Wadood A, Ahmed N, Shah L, Ahmad A, Hassan H, Shams S. In silico drug design: An approach which revolution arised the drug discovery process, OA Drug Design Delivery 2013;1:3-10.

21. Xiang M, Cao Y, Fan W, Chen L, Mo Y. Computer-aided drug design: lead discovery and optimazation. Comb Chem High Throughput Screening 2012;15:328-37.

22. Lipinski CA. Lead and drug like compounds; the rule of five revolution: drug. Discovery Today 2004;1:337-41.

23. Tetko IV, Bruneau P, Mewes H, Rohrer D, Poda G. Can we estimate the accuracy of ADMET predictions? Drug Discovery Today 2006;11:700-7.

24. Prasad G, Mahavir H, Balaji RA. Software based approaches for drug designing and development: a systematic review on commonly used softwares and its applications. Bull Faculty Pharm Cairo University 2017;55:203-10.

25. Patrick O, Mridula S, Wen Hui T, Hor KC, Kavitha G, Anand G. Invitri antidiabetic activity and in silico studies of binding energies of palmatine with alpha amylase, alpha glucosidase and DPP4 enzymes. Pharmacia 2020;67:363-71.

26. Abraham G, Yezyn G, Elix AD, Samuel E. Design, synthesis, antihyperglycemic studies and docking simulations of benzimidazole-thiazolidinedione hybrids. J Chem 2019;45:217-22.

27. Usha T, Shanmugarajan D, Goyal AK, Kumar C. Recent updates on computer aided drug discovery time for a paradigm shift. Curr Topics Med Chem 2017;17:3296-307. 